\title{
SOCIOLOGICAL CONSTRUCTION LINES. II
}

\section{SECTION IV. SOCIOLOGY A STUDY OF PROCESSES}

What, then, is it that the sociologist studies? Is there some special division or aspect of reality that is the object of his investigation, and, if so, what is it? The common and obvious answer is : "The sociologist studies society." The more elaborate and analytical answers, when their main contents are summed up, appear to have been twofold: first, the sociologist studies societies - social organisms, or at least organizations, groups of people among whom established relations exist; second, he studies social institutions-ideas, beliefs, customs, and habits, that have become common property throughout groups to which these institutions give character and a certain unity. Each of these answers contains a degree of truth. Not all of them together contain truth that is complete and exact enough to make a final answer to the question.

The sociologist is a student of processes. Sciences may begin with an examination, description, and classification of things; but all this is preliminary to a study of the processes that explain the things, the processes by which they have arisen and by which they are maintained and modified. We recall the time when natural history occupied itself with minute description and classification of animals and plants. Now, the chief objects of research in zoölogy and botany are the physiological processes that produce, maintain, and modify animals and plants. In the investigations that advance these sciences the main focus of attention has shifted from products to processes, from the plant that can be dried, labeled, and pigeonholed in an herbarium, to plant life. Not until the processes of being and becoming are the objects of our attention do we have any developed science of life, any real explanation of living objects. The transfer of the botanist's main attention from leaves, stems, and flowers to vital processes must be paralleled by a transfer of the chief attention of sociolo- 
gists from organizations and institutions to the processes of interaction that constitute the life of society.

There is a doctrine among philosophers that all our final knowledge of anything, living or not, is a knowledge of processes. They tell us that wherever there is a thing there is an activity of which the thing is the continuous result; and, if the thing is unchanging, that is because the activity is constant. Animal life is a highly complex process, comprising many subordinate processes: the beating heart, the circulating blood, the heaving lungs, peristalsis, osmosis, secretion, and the rest - a continual building up and tearing down of tissues of many kinds. Plant life is also a process, less complex and less obvious save to the botanist. In a dead animal or a log much of the activity has ceased, yet some still goes on. The gradual process of decay is not the only activity present in the $\log$; decay, is rather the disturbance of the activities that are present in the sound timber. In the sound wood hydrogen, carbon, and oxygen hold each other in a vigorous embrace, and if that embrace were loosened for an instant, the result we call wood would disappear. Moreover, the united hydrogen, carbon, and oxygen are in constant motion. It is when their union is violently broken down by enzymes, and the remnants are attacked by the avid oxygen, that decay takes place and log and wood cease. The very soil into which it crumbles is to be understood only in terms of process. It is when molecules are liberated from encumbrance by solution or fusion ${ }^{15}$ - that is, when the activities that constitute one kind of matter are not interrupted by those that constitute some other kind - that we get crystals. The absolute regularity and constancy of the process appears in absolutely regular shapes. The centers of activity push and pull each other just alike, and so hold each other fast in ranks and files. These centers of activity are the atoms; and physicists now tell us that atoms are systems of interacting electrons, and that electrons are vortices. ${ }^{16}$

${ }^{15}$ In fusion communicated motion appears so to reinforce the characteristic motion of molecules that they tear themselves free, and solution may well be due to a relation between the vibrations in the body dissolved and the vibrations in the solvent.

${ }^{16}$ This clause is inserted in deference to the recent discoveries in radio- 
We are given to understand that green and red are not qualities of inert matter, but results of motion. Fragrant and fetid, bitter, sweet, salt, savory, are results of chemical attacks upon the nerves of smell and taste. Heavy is a tug. Hot and cold are the vibration of molecules. Sounds loud and shrill are effects upon us of motions violent and swift; sounds soft and low, of motions slow and gentle. Every quality known to any sense of ours is the effect on us of action; and we know matter only by these sensations which nothing but action can stimulate. Hence, if the quality of a stone appears to us fixed and constant, that is because the activities that reach us from the stone are steady; as the earth seems solid and unstirred because its rush and whirl are without interruption, so the stone is to our senses an unchanging thing, because it is the expression of a steady and unjarring process. This theory of being implies that there are constant activities continually issuing in results that do not change, results that are commonly described as static phenomena; while there are also other activities which reveal their presence by frequent change, and it is these changing effects that are commonly called processes. But if this theory be true, then the static is everywhere a cross-section of the dynamic. Acceptance of this view suggests a corresponding view of the nature of science. Each thing being the result of a continuous process, the science that explains it must set forth the process of which it is an expression.

Science echoes back to Heraclitus his $\pi a ́ \nu \tau a ~ \chi \omega \rho \epsilon \hat{~}$. The whole activity. It is asserted that uranium, thorium, and radium, being elements, by the procedure of their own activities become transmuted into other substances which also are elements. The address of the president of the British Association for the Advancement of Science, published in the Popular Science Monthly for October, I904, contains the following: Gravitation, attraction, and repulsion between electrically charged bodies, molecular action, and chemical affinity are "the feebler forces of nature" and "sink into insignificance beside the attractions and repulsions between the electric monads themselves." "If the dust beneath our feet be indeed compounded of innumerable systems, whose elements are ever in the most rapid motion, yet retain through uncounted ages their equilibrium unshaken ..." "The new theory of matter analyzes matter, whether molar or molecular, into something which is not matter at all. The atom is now no more than the relatively vast theater of operations in which minute monads perform their orderly evolutions; while the monads themselves are not regarded as units of matter, but as units of electricity, so that matter is not merely explained, but explained away." 
is in flux; being is process, not fixity. Not alone the immovable earth spins on its axis and careers around the sun; the solar system sweeps through space, the fixed stars are not fixed, atoms are systems of interaction, and elements of elements are power. The soul of man we can know only as a concatenation of experiences. ${ }^{17} \mathrm{We}$ are a part of the never-ceasing change. Yet we need not be distraught, nor fear as if we were like land-birds driven out to sea where there is no solid thing to rest upon. Motion itself is fixity, the only fixity. Each atom in its place is more obedient than a Spartan hoplite. The process that we are is inflected into the processes of nature, and the One Force in which all things consist is self-consistent. Society is not an exception to all nature which knows no exceptions. Society is a process. A sociological problem is a glimpse of a process to be traced. As the psychologist does not study thought by describing thoughts that are written down in books, but by a study of thinking of which thought is the function, so the sociologist must be not merely a student of societies, in the popular sense, but a student of associating. Society is associates associating. To know what society is we must know what associating is. In order to render adequate the definition of sociology as "the study of society," it must be recognized that the word "society" in the definition is virtually a verbal noun. ${ }^{18}$

Whether or not we accept the metaphysic of power in its application to inorganic matter and the sciences of the inorganic, it is sufficiently plain that the sciences of life, at least, are studies of processes. Sociology is a science of life at its highest potency. It can find problems in the static, but not solutions; and cannot understand the problems until it looks upon that in society which seems most fixed as the evidence of a process to be discovered. This discovery is its real task; these processes are the true objects of the sociologist's attention.

${ }^{17}$ Wundt, Methodenlehre, Part IV, chap. 2, sec. $4 a$.

${ }^{18}$ As read in Chicago in the spring of 1902, this declaration closed this section, though, by a change of order, that which here follows had preceded it, except the two paragraphs which now conclude this section. The title then used was, "The Sociologists' Object of Attention." Secs. 5 ff., which will appear in later numbers of this Journal, were not read at that time, and only parts of them were written. 
The fact that even among those who have given the subject careful heed there is no clear and generally accepted notion as to what is the province of sociology, may be due to this, that the attempt has been to define a kind or aspect of accomplished facts instead of a kind of processes. Confusion would result among the material sciences if they should try to divide things among them. They would literally be reduced to fighting over the same bone. The biologist would, with indisputable right, claim every bone; but so also would the physicist claim it as a thing of hardness, impenetrability, and weight; and, with a claim equal to either, the chemist also, as so much lime. But between the three processes or kinds of action of which the bone is an expressiongrowth for the biologist, gravity for the physicist, and atomic affinity for the chemist - there is no confusion; and may not the difficulty as to just what is the province of sociology disappear as we adopt the true view, that here as there the objects of scientific study are processes?

Every science - or for us it suffices to say, every science of life-has its static and dynamic side. That is, it describes what it finds existent, sustained; and it also describes the processes by which all that is arose and is sustained. In other phrase, it describes beings, and aims to understand their being and their becoming; or, seeing what is, it asks how, that which is become, continues, and is transformed. In the static, the extant, the results of many processes and the problems of many sciences exist together in confusion; by distinguishing the processes, intelligibility and order emerge. The search for things rather than movements, groups and institutions rather than interactions, national societies rather than the foci of association, has baffled definition and confused analysis. Society must be both defined and analyzed, and it is society as a process, or as persons who carry on a process, that can be defined; and it is when the congeries of social phenomena is conceived in terms of process that it can be analyzed. The fundamental and apocalyptic analysis will be an analysis into the kinds of activity of which it is composed.

The static phenomena pertaining to society were studied before sociology came into existence, and will continue to be studied 
if no special science of sociology should be developed. Economic, political, juridical, linguistic, and religious institutions can be described without the existence of a special science to correspond to the name of sociology. But after this has been admitted, the question remains to be answered whether there does not exist a kind of processes which are not exclusively economic or political or religious, the results of which appear not in any single class of human institutions, but in them all; and requiring for its investigation a special science which is neither economics nor politics, nor any previously existing discipline, but sociology. If such processes exist, the results of their study might at length be taken up into the special social sciences to aid in the explanation of particular facts, as the results of pure geometry are taken up into the explanation of the particular facts of astronomy and physics. That would not make sociology any less a special science than geometry. The question is: Are there any kinds of social activity requiring investigation that is not limited by the horizon of any special social science? If such activities exist, then there is need of a special science of sociology.

Now, there is no difficulty in seeing that there are forces, factors, and processes that are active in producing and shaping social phenomena, and the effects which are not confined to the field of any one of the special social sciences. It seems not too much to say that all the processes of nature and human nature are actively shaping phenomena in the field of every social science; so that general sociology, if it is to be a study of the processes which shape social phenomena not of one sort, but of all sorts, and which are adequately traced by no one social science, must be a general philosophy; an attempt to account for human experience in the light of all science, synthesizing the results of all sciences by referring all discovered processes to their effect upon man. This is a possible view of the sociologist's task. But is there not a kind of processes which not only have social effects all natural processes do that - but also have a social origin and essence, which are not comprehended within the sphere of attention of any of the older sciences, but call for a new adjustment of attention? If these conditions are fulfilled, the sociologist, 
without waiving the right to construct a new philosophy, if he can, is also confronted with the task of developing a special science.

If there is any social process that fulfils these conditions, what is it? How can it be identified so as to become the object of our attention? An answer to this question that is likely to offer itself to the mind is, that the social process is social evolution, and that the special social sciences are related to sociology somewhat as the special sciences that treat of organic life are related to the study of biological evolution, which has contributed so much to the advancement of these sciences, but which itself still lacks so much of completeness and so urgently invites research. Whether this be the final answer to our query or not, the idea of social evolution is so important and interesting as to call for remark at this point, and, for the moment at least, we may use the phrase "social process" as equivalent to social evolution.

The "growth" 19 of a society does not mean mere increase in population, any more than the "growing up" of a child to manhood is mere increase in bulk into a two-hundred-pound infant, and societies are always growing, though their growth is not always progress. There is an onward and upward sweep in human affairs, but there are also retrograde movements. There are not only negative failure and lack, there are also positive harm and ruin included in the social process, and to be explained by knowledge of the principles of social causation. If the sociologist studies the processes in which human lives affect other human lives, he must recognize that men affect each other for evil as well as good. Association includes war and hate as well as love and beneficence. And the sociologist must study the whole process as it is, good and bad together. The immigrant who brought from a Moravian home a pietistic and refined conscience, and, settling in the slums of an American city, became depraved, exhibits a social phenomenon as really as another immigrant on whom a better phase of our civilization has produced an opposite effect. The depraving forces were all present in the complex

${ }^{19}$ Possibly we might receive a suggestion from the biologists' distinction between "growth" in mass and "development" in organization. 
American social process, and not to be omitted from any true account of it. Forces of evil are sometimes referred to as antisocial. That phrase misleads whenever, as has sometimes been the case, it conveys the impression that evil and forces of evil are not "social" phenomena, as well as good and the forces of good. Even the forces of good have in great measure been directed to their effect by no foresight and intention. The cumulative result of human progress or decline has in great part been due to the countless human interactions that have leaped forth with no judgment passed upon the motive and no calculation of the result. For example, the expressions that make up what we call unconscious influence, which create the social atmosphere, and mold the consciences of those who live in it, the panic that puts an army to rout, the courageous bearing that helps to save the day, the epidemic of crime, the waves of religious enthusiasm or of patriotism that sometimes sweep over a people - all these scantily illustrate the class of socially significant actions that are unintended; though when they exist on a great scale they are likely to become mixed with calculation.

Not only are unintended actions of great social significance, but still more significant are the unintended effects that issue from even the most deliberate deeds. Spencer remarks that the indirect and unforeseen results of social action are often, if not usually, more important than those intended. He applies the remark to the thoroughly considered enactments by which statesmen seek to influence social progress. How much more farreaching is the truth when applied to the deeds of the millions who design no far-reaching effects, but whose numberless activities are in fact incomparably more effective in determining the character of social growth than all the enactments of legislatures! Our knowledge of social causation has been so limited that the best-intended acts might unwittingly open a Pandora's box, while also beneficient consequences sometimes flow from follies, and even from sins. Lawmakers and agitators, clear of purpose but dim in their views of the social process, fail of their aims, but sometimes reach good that was not intended. And vastly more 
do the multitudes of men, each following his individual motive, work out the social changes.

As was made clear in the preceding section, the numberless social activities, mostly microscopic, but of continental magnitude in their fecund composition and combination, are not peculiar to established organizations or groups. Their effects are often indirect and circuitous, and the efficacy, both of the greater acts and of the seminal combinations of minute ones, traverses long intervals of space and time. Time and terrestrial space set us no boundaries. We are all day in social contact with the men of ages past and of every continent and clime. ${ }^{20}$ On rising I seize a sponge, by service of a South Sea Islander who got it for me from the ocean's floor; a cake of soap made by a Frenchman; a towel made by Turks. With each article of my apparel I receive the service of another group of my fellow-men. My underwear is from Scotchmen, or perhaps from Merino in Spain. My shoes' leather was stripped from the calf by Brazilian graziers, cut, lasted, and stitched by Yankees in Massachusetts. My coat is of wool from Australian rangers, carded, spun, and woven by Englishmen. To inventors, machinists, designers, web-drawers, weavers, I owe its fabric; to other such, its lining; to others, its silk braid and its canvas; its buttons of metal and mohair required the labors of yet other scattered companies. How many hands have touched some part of its material! How many brains have perfected the technique of all the processes of its manufacture! What an army in many detachments - some with fresh young faces, some with bent and toil-worn forms - do me service when I don my coat. Throughout the day the marvel does not cease. My breakfast orange was picked by a Florida negro; my coffee, raised by the brown folk of Java and Arabia; my steak comes from a Texas ranchman; my corn-roll, from a Kansas farmer. All have been assembled at my table by aid of those who tame the forces of nature, and build railroads and steamships, and of uncounted common men. Having received in the first hour of the day all these physical services, I take up the morning paper

${ }^{20}$ Compare Harris, Moral Evolution, p. 36, and Faucett, Manual of Political Economy, 6th ed., p. I 2 . 
and put myself into psychic contact with the world. It would require far too long a catalogue to recount how those who have made science and literature and art and customs and constitutions and laws throng about a common life throughout a common day; how our lives go on with all the earth and all the ages in one process; how we live under the influence of the lawmakers of England and of Rome, the artists of Greece, and the prophets and apostles of Israel, and how we share in their greatness. It is not alone the few pre-eminent souls that live pervasive and immortal. We each partake of the greatness of our race; and this, too, not alone in that we daily receive miraculous gifts for our physical and our spiritual lives, but also in the greatness of the service we return. Not Phidias only, but the mechanic of today, carving to the line the foreman drew - nay, the carrier of the mortargives immortality to the beauty that was Greece. The newsboy - thanks to Gutenberg and his successors - renders me an incredible service. And the mother in the nursery repeats the teachings of Christ, and as they fall from her lips they are as good as new and as potent of salvation. Like links in a chain we hang on all the past, and the future hangs on us. "Our generation is a parliament of timeless persons, of whom we, the living, are the least. By the fiction of death those are supposed to be absent who actually hold the balance of power." 21 And when we ourselves "join the majority" it will be a governing majority, for we then shall be a part of the past that will have created a new present. What that new present is to be waits on the actions of today. The social process is unbroken. In it we all enjoy an immortality that reaches backward so that we share the wisdom and inspiration of race-experience, and reaches forward into the greater blessing or the cursing for which we prepare.

The society we seek to understand is not so much a being as a becoming. That which becomes is human experience and activity of various types, to some of which we give the name of institutions. The causal conditions from which they emerge are more intricate than the causes of other phenomena, but perhaps not

\footnotetext{
${ }^{21}$ Professor Small in American Journal of Sociology, November, I900, p. 377.
} 
more fugitive, and may be even less difficult to observe than the conditions of physical life and growth and change. We are told that, by methods which we partly know and partly guess, and cannot wholly even guess, this physical world, with all its diversified and rich content, has been evolved from a monotonous mist that hung along the border-line between being and nonexistence. The social world has also had its evolution, dating from a time not so remote, and proceeding by methods which it is not rash to think are more accessible to investigation. And shall no worthy object of study be perceived in this evolution by which, from its poor precarious beginnings, the social world in which we live has risen? Bacon said truly that we are the true antiquity, and that which is called antiquity was the childhood of the race. It is only ignorance or predetermined blindness that can believe in a golden age that is somewhere behind us, and receding ever farther into the unreturning past, though "we may look backward for hope and cheer, since thus we see the direction of the journey of humanity." Already practical men and students of politics have begun to recognize, though inadequately, that there is a social process which it would be worth while to understand, which is not political nor national, but which underlies politics and affects that which is national; that a new law does not constitute a reform, but that reform is an effect of subtler agencies. The path of progress is smoothed not chiefly by the plow and roller of legislation, but, like the roads in central Africa, by the passing of many feet. This path-making sociology must understand and explain.

But however much we emphasize the idea of past social evolution, it does not by any means complete the concept of the social process. The feet of the many are always passing. The development of the social world goes on with ever-increasing complexity and multiplying possibilities of further advance. Therefore the study of social evolution is not a study of the past alone. Contemporary social causation is one with the process hitherto. And the social present is continuously caused. And even the social phenomena which are most nearly fixed and changeless are manifestations of the social process. 
Many persons, including Comte himself, have identified the dynamic conception of society only with the idea of society's evolution and change. The dynamic conception of society as here set forth has as much to do with permanence as with change. It has been said that even an unchanging stone can be conceived in terms of process, and certainly the most established social institution can be so conceived. An institution considered as established and permanent - for instance, the courts or the school system - would be called a static phenomenon by those who contrast the static with the dynamic, and identify dynamic phenomena only with change. But in reality such an institution is as really a dynamic phenomenon when thoroughly established as when it was in the act of coming into existence or is undergoing transformation. When thoroughly established, and as they say static, it has become a set of relatively constant and regular social activities.

Besides past evolution, then, the social process includes also contemporaneous social activity and causation. The former explains the difference between historic periods; the latter explains the difference between social classes. It is often the case that two families living in the same city ward, because of different operation of social causes, are separated by a gulf as wide as that between historic centuries. The differences are other than those between historic periods, but they are as real and as great. Some, identifying sociology with study of social evolution, care only for investigations of the past and the primitive, and center their attention chiefly on that which they recognize as good in the making. Others, intent on the problems of today, are impatient of such studies of the bygone and the primitive, and center their attention on the present, and often chiefly on what they recognize as present evil, and the question how it comes to miss the better that is so near it. To restrict the scope of sociology in either way is wrong by being only partly right. The social process is one. The stream of the social past debouches in the swirling present. The principles in operation are alike in both. To discover these principles is the aim of sociology. Once discovered, they may be applied to the solution of present problems, or to the construction of a scientific history. 
For the discovery of these principles, the study of the past and of the present have each some advantages that the other lacks. Our knowledge of the present is incomparably more complete than that which we can have of any past epoch. And our knowledge of the social movements in which we participate is more intimate than that which we can have of those which survive among backward peoples. On the other hand, in the past long sweeps of social causation can be traced, and the repetition of similar instances gives play to the comparative method, which reveals the essential and ever-present conditions of similar phenomena, and makes it possible to distinguish the nonessential elements of situations in which the phenomena are observed, affording an elimination of the accidental and isolation of the essential, like that effected in the laboratory. And from the highly evolved complexity of the present we can escape to the comparative simplicity of earlier stages.

Is the idea of the social process the answer to the question with which this section opened: What phenomena are the objects of the sociologist's attention? Is it enough to say in answer to the question: He is a student of the social process? And have we identified a kind of process which fulfils the conditions enumerated above, so as to require the existence of a separate science which is not economics or politics or any of the older special social sciences, but the newer science of sociology? This idea that the sociologist is not a student of things, of fixed results, but of a social process, which finds expression in all the phenomena that are studied by the special social sciences, and which in essence and method is not peculiar to any of them, but underlies them all this conception, when first it took shape in my mind, seemed to be the revelation for which I was striving. But further reflection raises further questions. This is not so much the recognition of a new kind of reality as further insight into familiar realities; and what it requires may not be a new science, but only completer adjustment of old ones to the evolutionary and dynamic point of view. The familiar phenomena of economics, politics, law, religion, etc., require to be studied as manifestations of process, the static as instantaneous photographs of the dynamic, the permanent 
as the constant function of regular and unintermittent activities. Emphasize the dynamic side as we will, yet it remains true that no process can be studied unless it "amounts to something." In more scientific phrase, a process can be identified only by its effects. Have we discovered any new kind of effects, or is it only that the familiar social sciences have been studying effects with inadequate attention to the processes of which they are the expressions, and that we have merely come to a more adequate realization that the fact of process characterizes social phenomena as it does other phenomena? Have we discovered a new kind of process, or merely come to realize that what we have been looking at all along was process, though we did not know it; that the very substance of these phenomena which we have been describing and trying to account for is the process that perpetually brings them forth? It need not daunt us to think that this view may require the familiar social sciences to undergo as complete a transformation as that which overtook the science of natural history, when it was reconstructed into biology by the transfer of attention to the study of processes. Ernst Haeckel for the physical scientists, and Wilhelm Wundt for the mental scientists, have said that, as the material sciences have had their blossomingtime in the nineteenth century, so the sciences of which sociology is the type, if not the sum, may be expected to have their blossoming-time in the twentieth. Before such prophecies can be fulfilled, long and wide avenues of further advance must be discerned. And it is not excessive optimism to hope that they will appear by the light of the dynamic conception of social phenomena. The candid admission that the social process shows its most important results in the fields already occupied by such sciences as economics, politics, and ethics, is not the same as saying that all existing phenomena have been adequately studied even by the static and "descriptive" method. Moreover, when the dynamic conception of social phenomena becomes habitual, it may be expected to lead to a shifting of appraisal such that facts hitherto regarded as relatively negligible will be seen to be important, and such that added to the present list of social sciences there may be one or more devoted to the study of social 
activities that have been regarded as too ephemeral or insignificant for serious study, but which illustrate the method of the social process, or contribute to the cumulative evolution which "cometh not with observation," but is of mightier significance than dramatic and eruptive events. But no such mere addition to the list of social sciences will constitute sociology. And the importance of the dynamic concept of society will not be confined to any such relatively new field of research; it already is distinctly appearing in the study of economic, political, legal, and ethical phenomena and in the history of religion, language, art, and science. The temporary confusion as to the proper scope and method of study in some of these fields, a feeling of the inadequacy of results hitherto attained, which exists in some quarters, and an increase of attention to the psychologic, that is the active, aspect of these phenomena, all are due in part to the dawning of the dynamic concept. To those who adopt this view as the guide of their investigations, the obvious interweaving of the social activities will forbid mutilating abstraction, and promote the growth of the realization that there is unity, or at any rate correlation, in the social process. And this realization may of itself suffice to create the need for the word "sociology" as a collective designation for the sciences that study this totality, which we indeed may analyze, in thought, for purposes of easier apprehension, but which, in fact, stubbornly retains its vast complexity.

The statement that the objects of sociological study are processes means that the students of the existing particular social sciences, as well as of branches of social investigation that may remain to be worked out, cannot find the objects of their most fruitful study in phenomena regarded as established, fixed, and static, be they never so monumental and institutional, but will find them rather in changes and the conditions of change which are often diffused, minute, and fleeting. It means also that which is yet more fundamental and significant, namely, that social phenomena are essentially activities, whether they are constant or whether they are changing, and that the most significant social causes are likewise activities. "Associating" is nothing apart 
from the various activities which people perform together, and these activities are economic, political, religious, etc., etc. Must sociology, then, be either a mere collective name for the particular social sciences taken together; or else a study of the crumbs that fall from the tables of these sciences - an investigation of neglected, subordinate, or primitive human activities? We must decline to accept, without further research, either of these views. Edward Cary Hayes.

Miami University. 